\section{Field methods in the evaluation of obesity in children and adolescents}

\section{Métodos de campo para a avaliação da obesidade em crianças e adolescentes}

Míriam Akemi Sampei 1

Dirce Maria Sigulem 2

1-2 Programa de Pós-Graduação em Nutrição. Escola Paulista de Medicina. Universidade Federal de São Paulo. Rua Marselhesa, 630. São Paulo, SP, Brasil. CEP: 04.020-060

E-mail: misampei@osite.com.br

\begin{abstract}
In large samples, the methods for obtaining information on obesity need to be simple, inexpensive and reasonably accurate. This review deals with articles focusing on various field methods for the evaluation of body composition. The Bioimpedance and Near Infrared methods are simple to execute but their advantage in relation to Body Mass Index is obscure. Although the Bioimpedance and near infrared methods provide estimates of fat content, they may be no better than waist circumference measurements. The latter does not distinguish body fat but points to a more direct relationship concerning health risk. Regardless of the advantages, waist circumference continues to be under discussion: there is a lack of standardization and no reference populations or cutoff points have been established. No perfect method exists, but the number of errors could be reduced, if care were taken in drawing up protocols, standardization, and the analysis of sample properties.
\end{abstract}

Key words Adolescent, Body Mass Index, Obesity, Methods

\section{Resumo}

Em amostras grandes, os métodos para se obter informações sobre a obesidade precisam ser simples, baratos e razoavelmente acurados. Essa revisão narrativa foi desenvolvida a partir de artigos e focará alguns métodos de campo para avaliação da composição corporal. Os métodos de Bioimpedância e do Infravermelho são de simples execução, baratos mas sua vantagem em relação ao Índice de Massa Corpórea é obscura. Apesar dos métodos de Bioimpedância e Infra-vermelho apresentarem estimativas da porcentagem de gordura, talvez não sejam superiores às medidas de circunferência da cintura. Essa não distingue a gordura corporal mas aponta para uma relação mais direta com o risco à saúde. Apesar das vantagens, a ciurcunferência da cintura continua em discussão: faltam as padronizações, o estabelecimento de populações de referência e pontos de corte. Não há método perfeito, mas os erros serão diminuídos se houver precaução na elaboração dos protocolos, na padronização e na análise das características da amostra.

Palavras-chave Adolescente, Índice de Massa Corporal, Obesidade, Métodos 


\section{Introduction}

At present, the world population is confronting an exorbitant increase in obesity and overweight in adults, children and adolescents and a proportional increase in chronic degenerative illnesses, such as cardiovascular diseases, diabetes and cancer has been reported. The identification of excess weight is important for diagnostic action and the prevention of diseases. Laboratory methods provide estimates of body fat close to that of reality, but are expensive and invasive. These methods do not have the agility of detection necessary for diseases such as obesity. With large samples, the methods for obtaining information on obesity need to be simpler, inexpensive, and to produce results with reasonable accuracy. Anthropometry is one of these methods and is based on the fact that, under normal nutritional conditions and an appropriate lifestyle, body measurements will develop adequately due to the total expression of genetic potential. Many difficulties are encountered in evaluating the anthropometric variables and body composition of adolescents. This is due to socioeconomic differences, the wide variation in the start time of the growth spurt and the variation in maturation rate and growth patterns among different ethnic groups within the population. In addition, in schoolaged children and adolescents the relationship of the Body Mass Index (BMI) and other anthropometric variables to body fat is more difficult to detect since degenerative diseases are accustomed to occur during later phases of life. Furthermore, although various studies have shown a weak relationship between BMI and the percentage of fat, $1-4$ there is strong evidence that ethnicity can interfere in this relationship.1,2,5,6 In addition, the existence of various references and different cut-off points for the classification of overweight and obesity make it difficult to choose the most appropriate reference and cut-off points in a study evaluating the nutritional status of an individual.

As well as anthropometry, there are portable machines in use that measure body fat. The accuracy of these methods has been studied, but their advantages in relation to anthropometry are as yet obscure. For example, the method of Bioimpedance (BIA) is very sensitive to body water variations. Thus, in adolescents, processes such as the development of body water content make the analysis of body composition components difficult.

Similarly, the Near Infra-red Interactance (NIR) method involves a portable instrument and is easy to repeat, but many studies have demonstrated that the NIR has a tendency to underestimate body fat.
In relation to Waist Circumference (WC), there is evidence showing that this anthropometric variable could be associated to health risk factors in adolescents. ${ }^{7,8}$ However, the heterogeneity of this age group has been an obstacle for the development of a single standard.

The BMI, WC, Bioimpedance methods and near infrared interactance are discussed in this review, with special attention being given to school-aged children and adolescents.

\section{Discussion}

\section{Body Mass Index}

The BMI has been the most widely used index because of its correlation with total body fat and with visceral fat, which is strongly associated with chronic degenerative illnesses. The risk association for such disorders and the BMI is well-established in adults. In children and adolescents, however, this correlation is difficult, since degenerative illnesses normally occur in the later phases of life. In view of this difficulty, the BMI for age has been recommended as the best indicator for children and adolescents, since it incorporates information regarding age. ${ }^{9}$ The BMI has also been validated as a total body fat index at the extreme percentiles. The values of this indicator need to be compared with those of the reference standard in order to verify the degree of adjustment between them. There are various reference standards on the distribution of BMI values for determining obesity and overweight in adolescents. The most widely used are outlined below:

\section{Reference data for BMI in adolescents}

\section{- World Health Organization (WHO) References}

The WHO adopted the reference from the National Center of Health Statistics (NCHS), data for which was collected during the National Health and Nutrition Examination Survey, NHANES I survey (1971-1974). These followed the criteria proposed by Must et al., 101991 . The cut-off points of $85^{\text {th }}$ and $95^{\text {th }}$ percentiles were selected even though they were not directly associated to health risks in children and adolescents. The World Health Organization, 1995, recommended the combination of high BMI values ( $>85$ percentile) and high subcutaneous fat for the definition of obesity. 11 High subcutaneous fat was defined as both subscapular and tricipital skinfolds, above the $90^{\text {th }}$ percentile in the NCHS reference 
data. The combination of these two indicators had as its objective the maximizing of specificity, identifying those adolescents who are overweight and overfat.

- Center for Disease Control and Prevention of the United State (CDC-US References)

The growth charts of the CDC-US are a revised version of the 1977 National Center for Health Statistics (NCHS) growth charts. 12 This version includes the BMI distribution in percentiles for the age range 2-19 years. The values were based upon data from the US Health Examination Surveys that incorporated data from the National Household Education Surveys Program, NHES I (1963-1965) and III (1966-1970), NHANES I (1971-1974), II (1976-1980) and III (1988-1994). The NHANES III data on children $\geq 6$ years was not included in the reference population due to a growing tendency towards overweight in the children covered by that survey. Using this as a point of reference, overweight and obesity were defined by the $85^{\text {th }}$ and $95^{\text {th }}$ percentiles respectively. Thinness was defined by the 5 th percentile.

\section{- International Obesity Task Force References}

The cut-off points of the $85^{\text {th }}$ and $95^{\text {th }}$ percentiles, as recommended by the WHO and CDC-US have been statistically established. Thus the prevalence towards overweight and obesity remains the same for all ages and both genders. Because populations may change over time, a further problem arises if new standards are based on current data, in that the use of current data to establish standards eliminates the capacity to show trends over time. 13 Therefore, percentiles should be based on a reference population that does not change over time. A percentile cut-off point could in theory be identified as the point in the distribution of BMI where the health risks arising from obesity start to rise steeply. Children tend to retain the same BMI percentile throughout their growth. The association between child obesity and health risk could well be measured through adult obesity, which is associated with both child obesity and adult illness. ${ }^{14}$ Based upon these facts, a workshop organized by the International Obesity Task Force (IOTF) proposed that these adult cut-off points be linked to BMI percentiles for children in order to provide cut-off points for children.

The IOTF established cut-off points based on the percentiles that passed through the BMI of $25 \mathrm{k} \mathrm{g} / \mathrm{m}^{2}$ or $30 \mathrm{~kg} / \mathrm{m}^{2}$ at 18 years of age, in order to define overweight and obesity, respectively. The reference population is based on international data collected in different countries (Brazil, Great Britain, Hong Kong, Holland, Singapore and the United States). The proposed cut-off points are less arbitrary and more international than those currently prevailing.

- The new WHO growth reference for school-aged children and adolescents (2007, WHO)

The development of an international growth standard for the screening, surveillance, and monitoring of school-aged children and adolescents was motivated by two contemporaneous events, 15 the global surge in childhood obesity and the release of a new international growth standard for infants and preschool children by the WHO. 16

The new WHO growth reference for school-aged children and adolescents is closely aligned to the WHO Child Growth Standards at five years, 16 and the recommended adult cut-offs for overweight and obesity at 19 years. In this way, the WHO proceeded to reconstruct the $1977 \mathrm{NCHS} / \mathrm{WHO}$ growth reference from 5 to 19 years, using the original sample merged with data from the WHO Child Growth Standards to smooth the transition between two samples. State-of-the-art statistical methods were used on this merged sample. Onis et al.,15 2007, have concluded that the new curves fill the gap in growth curves and provide an appropriate reference for the 5 to 19 year age group.

\section{Considerations about the three BMI reference standards}

Various studies have demonstrated differences between the prevalences produced by the use of these three references. The reference values of Cole et al. (2000), 14 provide lower estimates than the growth charts of the CDC-US and the values produced by Must et al. (1991) 10 for small children, but provide larger estimates for older children. 17,18 The choice of reference and cut-off points mainly depends upon the objective of each study. If there is to be an international comparison, perhaps the best reference would be that of Cole et al. (2000). ${ }^{14}$ Various authors, nevertheless, have criticized the proposal made by Cole et al. (2000). ${ }^{14}$. Hesketh, in a letter to the editor of British Medical Journal (BMJ), in 2000,19 argued that the Hong Kong sample was not representative of the Chinese population, as taken to be the case by Cole et al. (2000). 14 Kinra, (2000) 19 in a letter to editor of the BMJ, argued that in a reference based on a single population, the user 
is able to predict the direction of the deviation, which becomes difficult in a mixed population. As well as this, Kinra (2000)19 mentioned that age differences in the start of puberty from one population to another could be related to socioeconomic status. He stressed that five of the six reference countries has a gross national product higher than that of most African and Asian countries. The majority of child obesity cases appear during puberty, and it is during this phase that the new redefinition runs the greatest risk of error.

If the focus is on international comparisons, then perhaps the best reference is that of Cole et al. (2000). ${ }^{14}$ For clinical use, however, the other references are probably more appropriate.

\section{BMI accuracy in evaluating body fat}

Authors have demonstrated that the BMI errs in not detecting a large number of obese individuals. In fact, for a given BMI there can be a wide variation in the percentage of fat, ranging from low to high.1,20,21 There is also uncertainty arising from the dependence of the BMI on height. In adults it is dependent on height, but in children and adolescents this is not necessarily true. 22 Also, the relationship between BMI and fat and fat-free body-mass components is complicated by the variation in growth rates and maturity levels. Maynard et al. (2001)20 suggested that boys that are taller at the onset of adolescence may have higher BMI values due to increased height and not necessarily for reason of adiposity.

The relationship of BMI to body fat is not stable over time. Wells et al. (2002)21 have demonstrated that a contemporary child has a different adiposity for a given BMI value when compared to the reference child of two decades ago.

Additionally, there is evidence that ethnicity could affect the relationship of BMI and fat percentage. 1,2,5,6 Some studies indicate that, for the same BMI, Asians have more body fat than Caucasians. 1,2,5,6 The medical-scientific community has witnessed an intense debate regarding the revision of overweight and obesity cut-off points for Asians. ${ }^{23}$, The decision to lower the cut-off points for Asian adolescents is more difficult than for adults, since there is no clear association between $\mathrm{BMI}$ and illness risk during this phase of life.

\section{Waist circumference (WC)}

One indicator that stands out in the detection of risk of chronic degenerative illnesses is WC. This measurement is an intra-abdominal adipose mass and total adipose mass index, which is correlated with the BMI and is independent of height. Various studies have shown the "superiority" of the WC over the BMI

The major value of the WC has been as a characteristic for the definition of metabolic syndrome. In 1998, the WHO defined this syndrome using measurements for glucose intolerance or insulin resistance. ${ }^{24}$ Later, the $\mathrm{WC}$ was adopted by the WHO in a revised version. 25 During 2001, the Third Report of the National Cholesterol Education Program Expert Panel on Detection, Evaluation and Treatment of High Blood Cholesterol in Adults (NCEP ATP III) defined metabolic syndrome to include, as well as the analysis of blood pressure and blood content, the measurement of the WC. The cutoff points proposed by the NCEP ATP III, namely, $102 \mathrm{~cm}$ for men and $88 \mathrm{~cm}$ for women, 26 were selected, in view of their correlation with those for BMI distribution indicating overweight and obesity. In 2005, the International Diabetes Foundation (IDF), in an attempt to create a universal definition, redefined metabolic syndrome taking central obesity, which is measured using the $\mathrm{WC}$, as an obligatory criterion. 27 The cut-off points for Caucasians were lower than those of the NCEP ATP III. They were also dependent upon ethnicity.

Katzmarzyk et al., (2006)28 examined the effects of the WC on the mortality rate of 20,789 men, following the criteria for metabolic syndrome defined by the NCEP, revised in the NCEP and IDF.

The results of these studies showed that WC plays an important role among the clinical criteria for metabolic syndrome.

Cheung et al., (2006) 29 compared the prevalence of the metabolic syndrome in the NHANES 19992002 following the criteria of the WHO, NCEP Panel III and IDF definitions. The authors concluded that the $\mathrm{WC}$, since it is a pre-requisite, did not affect the diagnosis of metabolic syndrome in the United States. Nevertheless, in other ethnic populations, such as Asians, the new WC criteria from the IDF could significantly alter the prevalence of metabolic syndrome. The use of lower WC cut-off points for Asians has also been investigated by other authors. ${ }^{30,31}$ In other ethnicities, differences have also been verified. 32

There is evidence showing that the WC may be associated with health risk factors in adolescents. ${ }^{7-8}$ However, the heterogeneity of this age group has been an obstacle for the development of a single standard. Another important question concerns the 
reference data for WC. 33 There were attempts in the past to generate standardized reference data, but these references failed to include non-white populations. Additionally, the use of different anatomical sites for the measurements of WC has caused confusion. For example, Wang et al., (2003) 34 compared the WC measurements at the four most diverse points: immediately below the lowest ribs, the point where the waist is narrowest, the midpoint between the lowest ribs and the iliac crest, and immediately above the iliac crest. The WC measurement values at these sites differed according to sex, were easy to reproduce and had a correlation with total body fat and of the trunk in a sex-dependent manner.

Various percentile distributions for WC have been proposed as a standard for children and adolescents. Freedman et al., (1999)35 investigating associations between WC and lipid and insulin concentrations in children and adolescents in the Bogalusa Heart Study, showed that the WC possesses the highest association with concentrations that constitute a risk factor. These authors presented WC measurements in the 50 and 90 percentiles as a function of ethnicity, sex and age.

Taylor et al., (2000)36 evaluated the competence of the WC, the waist/hip proportion and index coincidence in identifying children with a high degree of fat in their trunk measured using the DXA. The WC was a good central obesity indicator in children and adolescents of both sexes and over a wide age range. The best cut-off point in the study was the $80^{\text {th }}$ percentile. The study performed by Fernandez et al. (2004) 37 was more complete from the ethnic point of view as its distribution of WC in percentiles included Mexican Americans, African Americans and European Americans. The results of this study have demonstrated that the distribution of WC in children and adolescents in the United States differs according to ethnicity.

Ferranti et al. (2004) 38 proposed a definition of metabolic syndrome based on the ATP III and using data from the NHANES III. The authors used WC distribution percentiles comparable to those of Caucasian men in the $70^{\text {th }}$ percentile.

Rosa et al., 200739 have evaluated the sensitivity and specificity of waist circumference measurements in a sample of 456 Brazilian adolescents. They verified that the existing American WC cut-off points showed low sensitivity and specificity for hypertension in Brazilian adolescents. For this reason, the establishment of standards and cut-off points for adolescents is very important.

The difficulty is to establish cut-off points for WC that reflect the risk factors for the chronic degenerative diseases in this age group.

Traditionally, obesity has been defined using the BMI, although, evidence suggests that measurements such as those of the WC are more significant predictors of the risk of chronic degenerative illness.

\section{Bioimpedance (BIA)}

The evaluation of the body composition via bioimpedance involves passing an electric current, of low intensity $(800 \mu \mathrm{A})$ and of fixed frequency $(50 \mathrm{kHz})$, through the individual's body. When an electric current is applied to the body, there is opposition to the flow that is called resistance. The drop in voltage between the electrodes provides a measurement of impedance, which is the vector sum of the resistance or conductivity properties of the body tissue and the reactance due to the capacitance of the cell membranes. The water inside is a good conductor of electricity. Muscle mass, like other tissues, is full of electrolytes and water, offering little resistance to the passage of an electrical current. Fat possesses an almost zero index of hydration, and thus has high bioimpedance. Muscle therefore conducts electricity more easily than fat. The bioimpedance body tissues thus provides an estimate of total body water (TBW). ${ }^{40}$ For this estimate, the human body needs to be represented as a single uniform cylinder. Additionally, the hydration of the tissues must be constant and the electrical frequency needs to penetrate equally into all the cells. Not one of these generalizations is entirely valid. 41 Notwithstanding these limitations, a relationship between the impedance quotient ( $\mathrm{L} 2 / \mathrm{R}$, where $\mathrm{L}=$ length and $\mathrm{R}=$ resistance) and the volume of water can be established. The quantity of Fat-Free Mass (FFM), is estimated knowing that the TBW constitutes $73 \%$ of the FFM. Fat content can be estimated by the difference between total weight and the quantity of FFM.

Some technological advances have been made in order to diminish BIA errors. One of these changes is based on the differentiation between the TBW components, that is to say, the water inside and outside the cell. This is made possible by replacing the model involving resistors in a series with a model involving resistors in parallel. In the parallel model, two or more resistors and capacitors are connected in parallel, with the current passing at high frequencies by way of the intra-cellular space and at low frequencies by way of the extra-cellular space. 41,42 In BIA at a single frequency of $50 \mathrm{kHz}$, the current moves through both the intra-cellular fluid and the extra-cellular fluid, although this varies 
from one kind of tissue to another. BIA methods using multiple frequencies have been developed. Despite single frequency BIA being popular for evaluating fat content and FFM, the use of multifrequency BIA is especially recommended if the prediction of body water compartments is required. 43

Dozens of equations exist for estimating the TBW and FFM as a function of impedance, weight, height, age and sex. The choice of equations is difficult in the case of adolescents, as they are still maturing sexually and in terms of body water and body composition.

Body fat is not measured, since it is not a conductor. Thus, whatever estimate of body fat using BIA is subject to cumulative errors associated with the prediction of FFM. This is a limitation of all twocompartment models $($ Weight $=$ FFM + Fat $)$. The two-compartment models assume a constant FFM composition and therefore do not distinguish differences in body composition due to factors such as physical activity, illness and ageing. These limitations can be overcome by using a multi-compartment model that considers the differences between individuals in the chemical composition of the FFM. 44

Studies have shown that the BIA gives good results. 1,2,6,45-47 The NHANES III included the BIA in its survey, owing to dissatisfaction with the trustworthiness of the skinfolds and with the inability to obtain estimates of lean and fat masses. 48 In order to make use of the BIA data of the NHANES III, an external group of BIA equations was developed with the use of isotope dilution for predicting the TBW. In addition to this, a multi-compartment model was used to predict the FFM. 49 These equations provided estimates for the principal body compartments of non-Hispanic Whites, non-Hispanic Negroes and Mexican-Americans with an age range of 12-80 years, as part of the NHANES III.

Despite the existence of the studies that favor the use of the BIA, various authors have not found positive results. 50,51 Some point out that the BIA is not superior to the BMI.51 Other authors show low agreement of the BIA with more sophisticated models for evaluation of body composition. 52 Other authors discuss the influence of ethnicity 5,53 or the specificity of equations. 54

The foot-to-foot system, possesses advantages when used with large samples, which overcome the operational performance of the conventional BIA method.1,2,6,12,55-57 Nevertheless, some authors suggest that there is divergence and low agreement between the foot-to-foot system and more sophisticated body evaluation methods. 52,58

Sources of variance, such as blood viscosity, skin temperature, location of electrodes, state of hydration, meal and exercising all affect the impedance values and need to be taken into account in studies of this kind.

\section{Near infra-red interactance (NIR)}

During the 1980's, the NIR method was developed at the Instrument Research Laboratory of the United States Department of Agriculture. The method has become widely used, as it has proved to be quick, non-invasive, safe and relatively low-cost. This technology is marketed in the form of a portable batteryoperated machine, which performs satisfactorily for field work and clinical studies. The method is based on the principles of absorption, reflection of light and of near infrared spectroscopy. The method allows for analysis of body composition, since different types of tissue absorb light at different wavelengths. Pure fat absorbs light at $930 \mathrm{~nm}$, whilst water absorbs it at $970 \mathrm{~nm}$. The instrument contains a monochromatic wave emitter (linear range from $600 \mathrm{~nm}$ to $2500 \mathrm{~nm}$ ) and an optical fiber probe, which conducts radiation (average range between $700 \mathrm{~nm}$ and $1100 \mathrm{~nm}$ ) running from the emitter to a selected location on the body (biceps) capturing the interactive radiation. 59 The variation in the emitted spectrum, arising from the absorption of part of the light by the fat, creates a single spectrum standard that makes it possible to measure the percentage of fat.

Studies have obtained good results using the NIR method. 60 However, other studies have not reached satisfactory conclusions. 1,2,61 The majority of these studies highlight the under-estimation of fat content. Thomas et al. (1997)61 compared the NIR method with other body composition evaluation techniques on 43 adults. The study showed that the NIR underestimated the fat content by around $15 \%$ in comparison with other methods. These authors showed that although there was a high correlation between the optical density of NIR and the percentage of fat, the inclusion of other parameters in the calibration of the equation was necessary. The optical data on its own was not sufficiently precise or accurate to determine the quantity of body fat.

In spite of being an apparatus that is easy to handle, more widespread use is hampered by various disadvantages, such as the under-estimation of medians at the extremities of a variation continuum of body fat; serious prediction errors and the relatively high cost. 


\section{Conclusions}

This review has considered the advantages and disadvantages of the various methods for evaluating body fat. The choice of method will depend upon the research objectives for which the method will be used, the cost, the acceptance by participants, the ease of handling and measurement accuracy. Although the BIA and NIR measurements provide estimated percentage values for fat, they may not be superior to WC measurements. The latter does not distinguish total body fat but suggests a more simple and direct relationship in terms of health risk. Additionally, the WC has operational advantages such as the ease of measuring and low cost. In spite of the advantages, the use of WC is still being debated. There is a lack of standardization and reference populations and cut-off points for children and adolescents have not been established. The BMI has been criticized, but at population level, the accep-

\section{References}

1. Sampei MA, Novo NF, Juliano Y, Colugnati F, Sigulem DM. Anthropometry and body composition in ethnic Japanese and Caucasian adolescent girls: considerations on ethnicity and menarche. Int J Obes Relat Disord. 2003; 27 : 1114-1120.

2. Sampei MA, Novo NF, Juliano Y, Sigulem DM. Comparison of the body mass index to other methods of body fat evaluation in ethnic Japanese and Caucasian adolescent girls. Int J Obes Relat Disord. 2001; 25: 400-8.

3. Mei Z, Grummer-Strawn LM, Pietrobelli A, Goulding A, Goran MI, Dietz WH. Validity of body mass index compared with other body composition screening indexes for the assessment of body fatness in children and adolescents. Am J Clin Nutr. 2002; 75: 978-85.

4. Taylor RW, Jones IE, Williams SM, Goulding A. Body fat percentages measured by dual-energy X-ray absorptiometry corresponding to recently recommended body mass index cutoffs for overweight and obesity in children and adolescents aged 3-18 y. Am J Clin Nutr. 2002; 76: 1416-21.

5. Deurenberg P, Deurenberg_Yap M. Validity of body composition methods across ethnic population groups. Acta Diabetologica. 2003; 40:S246-S249.

6. Sampei MA, Novo NF, Juliano Y, Sigulem DM. Anthropometry and body composition in ethnic Japanese and Caucasian adolescent boys: considerations on ethnicity and maturation. Pediatr Int. 2008 [DOI: 10.1111/j.1442200x.2008.002633.x] [serial online]. [consulted on: 2008 Jun 19]. Available from: http://dx.doi.org/10.1111/j.1442200X.2008.002633.x

7. McCarthy HD. Body fat measurements in children as predictors for the metabolic syndrome: focus on waist circumference. Proc Nutr Soc. 2006; 65:385-92. tance of the BMI is much easier than the $\mathrm{WC}$; some participants, who are obese and shy, feel uncomfortable having their waist measured. Thus, when choosing a method, the characteristics of the sample must also be taken into consideration. There is no perfect method, but errors could be reduced, if precautions are taken in drawing up protocols, in standardization and in the analysis of sample properties, such as sex, maturity, ethnicity, and socialeconomic level. All of these aspects could interfere in the measurement and in its relationship to body composition and risk factors.

\section{Acknowledgements}

We would like to thank Coordenação de Aperfeiçoamento de Pessoal de Nível Superior (CAPES) for the provision of grants and financial aid.
8. Maffeis C, Pietrobelli A, Gressani A, Provera S, Tarô L. Waist circumference and cardiovascular risk factors in prepubertal children. Obes Res. 2001; 9:179-187.

9. Himes JH, Bouchard C. Validity of anthropometry in classifying youths as obese. Int J Obes. 1989; 13:183-93.

10. Must A, Dallal GE, Dietz WH. Reference data for obesity: $85^{\text {th }}$ and $95^{\text {th }}$ percentiles of body mass index (wt/ht 2$)$ and triceps skinfolds thickness. Am J Clin Nutr. 1991; 53: 83946.

11. Johnson CL, Fulwood R, Abraham S, Bryner JD. Basic data on anthropometric measurements and angular measurements of the hip and knee joints for selected age groups 174 years of age. Vital Health Stat. 1981; April (219):1-68.

12. Kuczmarsk, RJ, Ogden CL, Grummer-Strawn LM, Gligal KM, Guo SS, Weir, Nei R, Curtin LR, Roche AF, Johnson FL. CDC growth charts: United States. Adv Data. 2000; 314: 1-27.

13. Bellizzi MC, Dietz WH. Workshop on childhood obesity: summary of the discussion. Am J Clin Nutr. 1999; 70: S173-5S.

14. Cole TJ, Bellizzi MC, Flegal KM, Dietz WH. Establishing a standard definition for child overweight and obesity worldwide: international survey. BMJ. 2000; 320: 1-6.

15. Onis M, Onyango AW, Borghi E, Siyam A, Nishida V, Siekman J. Development of WHO growth reference for school-aged children and adolescents. Bull WHO. 2007; 85: 660-7.

16. WHO (World Health Organization), Multicentre Growth Reference Study Group. WHO child growth standards based on length/height, weight and age. Acta Paediatric. 2006; 450 (Suppl): 76-85. 
17. Wang Y, Wang JQ. A comparison of international references for the assessment of child and adolescents overweight and obesity in different populations. Eur J Clin Nutr. 2002; 56 : 973-82.

18. Rolland-Cachera M-F, Castetbon K, Arnault N, Bellisle F, Romano M-C, Lehingue Y, Frelut M-L, Hercberg S. Body mass index in 7-9-y-old French children: frequency of obesity, overweight and thinness. Int J Obes Relat Metab Disord. 2002; 26: 1610-6.

19. Wang Y, Wang J, HeskethT, Ding QJ, Mulligan J, Kinra S, Standard definition of child overweight and obesity worldwide [letter]. BMJ. 2000; 321: 1158-1159.

20. Maynard LM, Wisemandle W, Roche AF, Chumlea C, Guo SS, Siervogel RM. Childhood body composition in relation to Body Mass Index. Pediatrics. 2001; 107: 344-50.

21. Wells JCK, Coward WA, Cole TJ, Davies PSW. The contribution of fat and fat-free tissue to body mass index in the contemporary children and the reference child. Int J Obes. 2002; 26: 1323-8.

22. Garn SM, Leonard MA, Hawthorne VM. Three limitations of the Body Mass Index [editorial]. Am J Clin Nutr. 1986; 44: 996-7.

23. Anuurad E, Shiwaku K, Nogi A, Kitajima K, Enkhmaa B, Shimono K, Yamane Y. The new criteria for Asian by Regional Office for the Western Pacific Region of WHO are suitable for screening of overweight to prevent metabolic syndrome in elder Japanese workers. J Occup Health. 2003; 45: 335-3.

24. Alberti KGMM, Zimmet PZ. For the WHO consultation: definition, diagnosis, and classification of diabetes mellitus. Provisional report of a WHO Consultation. Diabet Med. 1998; 15: 539-53.

25. Balkau B, Charles MA. Comment on the provisional report from the WHO consultation European Group for the Study of Insulin Resistance (EGIR). Diabet Med. 1999; 16: 4423.

26. National Cholesterol Education Program. National Heart, Lung, and Blood Institute. Executive Summary of the Third Report of the National Cholesterol Education Program (NCEP). Expert painel on detection, evaluation, and treatment of high blood cholesterol in adults (adult treatment panel III). JAMA. 2001; 285: 2486-97.

27. Alberti G, Zimmet P, Shaw J. A new IDF worldwide definition of the metabolic syndrome: the rationale and the results. Diabetes Voice. 2005; 50: 31-3.

28. Katzmarzyk P, Janssen I, Ross R, Church TS, Blair SN. The importance of waist circumference in the definition of metabolic syndrome: prospective analyses of mortality in men. Diabetes Care. 2006; 29: 404-9.

29. Cheung BM, Ong KL, Man YB, Wong LY, Lau CP, Lam KSJ. Prevalence of the metabolic syndrome in the United States National Health and Nutrition Examination Survey 1999-2002 according to different defining criteria. Clin Hypertens. (Greenwich). 2006; 8: 562-70.

30. Tan CE, MAS, Wai D, Chew SK, Tai ES. Can we apply the National Cholesterol Education Program Adult Treatment Panel definition of the metabolic syndrome to Asians? Diabetes Care. 2004; 27: 1182-6.

31. Japan Society for the Study of Obesity. Committee of Criteria for "Obesity Disease". New criteria for obesity disease in Japan. Circ J. 2002; 66: 987-92.
32. Lee S, Bacha F, Gungor N, Arslanian AS. Waist circumference as an independent predictor of insulin resistance in black and white youth. J Pediatr. 2006; 148: 188-94.

33. Wang J. Standardization of waist reference data. Am J Clin Nutr. 2006; 83: 3-4.

34. Wang J, Thornton JC, Bari S, Williamson B, Gallagher D, Heymsfield SB, Horlick M, Kotler D, Laferrare B, Mayer L, Pi-Sunyer FX, Pierson RN. Comparisons of waist circumferences measured at 4 sites. Am J Clin Nutr. 2003; 77: 379-84.

35. Freedman DS, Serdula MK, Srinivasan SR, Berenson GS. Relation of circumferences and skinfold thicknesses to lipid and insulin concentrations in children and adolescent: the Bogalusa heart study. Am J Clin Nutr. 1999; 69: 308-17.

36. Taylor RW, Jones IE, Williams SM, Goulding A. Evaluation of waist circumference, waist-to-hip ratio, and the conicity index as screening tools for high trunk fat mass, as measured by dual-energy X-ray absorptiometry, in children aged 3-19 y. Am J Clin Nutr. 2000; 72: 490-5.

37. Fernández JR, Redden DT, Pietrobelli A, Allison DB. Waist circumference percentiles in nationally representtive samples of African-American, European-American, and Mexican-American children and adolescents. J Pediatr. 2004; 145: 439-44

38. Ferranti SD, Gauvreau K, Ludwig DS, Neufeld EJ, Newburguer JW, Rifai N. Prevalence of the metabolic syndrome in American adolescents finding from the Third National Health and Nutrition Examination Survey. Circulation. 2004; 110: 2494-7.

39. Rosa MLG, Mesquita ET, Rocha ERR, Fonseca VM. Índice de massa corporal e circunferência da cintura como marcadores de hipertensão arterial em adolescentes. Arq Bras Cardiol. 2007; 88: 573-8.

40. Bioelectrical impedance analysis in body composition measurements; National Institutes of Health Technologu Assessment Conference Statement. Am J Clin Nutr. 1996; 64 (Suppl.): 524S-32.

41. Ellis KJ, Bell SJ, Chertow GM, Chumlea WC, Knox TA, Kotler DP, Lukaski HC, Schoeller DA. Bioelectrical impedance methods in clinical research: a follow-up to the NIH Technology Assessment Conference. Nutrition. 1999; 15:874-80.

42. Kyle UG, Bosaeus I, De Lorenzo AD, Deurenberg P, Elia M, Gómez J M, Heitmann BL, Kent-Smith L, Melchior JC, Matthias P, Scarfetter H, Schols AMWJ, Pichard C. Bioelectrical impedance analysis - part I: review of principles and methods. Clin Nutr. 2004; 23:1226-1243.

43. Ward LC, McGill A-T, Leahy FE, Poppitt SD. Multiple and single frequency bioelectrical impedance (BIA) methods are not interchangeable for the prediction of body fluid volumes in overweight individuals. Asia Pac J Clin Nutr. 2003; 12 (Suppl): S55.

44. Sun SS, Chumlea WC, Heymsfield SB, Lukaski HC, Schoeller D, Friedl K, Kuczmarski RJ, Flegal KM, Johnson CL, Hubbard VS. Development of bioelectrical impedance analysis prediction equations for body composition with the use of a multicomponent model for use in epidemiologic surveys. Am J Clin Nutr. 2003; 77: 331-40.

45. Shaikh MG, Crabtree NJ, Shaw NJ, Kirk JM. Body fat estimation using bioelectrical impedance. Horm Res. 2007; 68: $8-10$ 
46. Goldfield GS, Cloutier P, Mallory R, Prud' Homme D, Parker T, Doucet E. Validity of foot-to-foot bioelectrical impedance analysis in overweight and obese children and parents. J Sports Med Phys Fitness. 2006; 46: 447-53.

47. Pateyjohns IR, Brinkworth GD, Buckley JD, Noakes M, Clifton PM. Comparison of three bioelectrical impedance methods with DXA in overweight and obese men. Obesity. 2006; 14: 2064-70.

48. Kuczmarski RJ. Bioelectrical impedance analysis measurements as part of national nutrition survey. Am J Clin Nutr. 1996; 64: S453-8.

49. Chumlea WC, Guo SS, Kuczmarski RJ, Flega KM, Johnson CL, Heymsfield SB, Lukaski HC, Friedl K, Hubbard VS. Body composition estimates from NHANES III Bioelectrical Impedance Data.. Int J Obes Relat Metab Disord. 2002; 26: 1596-609.

50. Körner A, Gelbrich G, Müller G, Reich A, Deutscher K, Gödicke R, Gronemann B, Kiess W. Contra critical evaluation of methods for determination of body fat content in children: back to basic parameters? Horm Metab Res. 2007; 39: 31-40.

51. Willett K, Jiang R, Lenart E, Spiegelman D, Willett W. Comparison of bioelectrical impedance and BMI in predicting obesity-related medical conditions Obesity. 2006; 14: 480-90.

52. Chouinard LE, Schoeller DA, Watras AC, Clark RR, Close RN, Buchholz AC. Bioelectrical impedance vs fourcompartment model to assess body fat change in overweight adults. Obesity. 2007; 15: 85-92.

53. Takasaki Y, Loy SF, Juergens HW. Ethnic differences in the relationships between bioeletrical impedance and body size. J Physiol Anthropol Appl Human Sci. 2003; 22: 233-5.
54. Ward LC, Heitmann BL, Craig P, Stroud D, Azinge EC, Jebb S, Cornish BH, Swinburn B, O'dea K, Rowley K, Mcdermott R, Thomas BJ, Leonard D, Association between Ethnicity Body Mass Index, and Bioelectrical Impedance: implications for the population specificity of prediction equations. Ann NY Acad Sci. 2000; 904: 199-202.

55. Dixon CB, Andreacci JL, Goss FL. The effect of acute fluid consumption on measures of impedance and percent body fat using leg-to-leg bioelectrical impedance analysis. Eur J Clin Nutr. 2006; 60: 142-6.

56. Nuñez C, Gallangher D, Visser M, Pi-Sunyer FX, Wang Z, Heymsfield SB. Bioimpedance analysis: evaluation of legto-leg system based on pressure contact foot-pad electrodes. Med Sci Sports Exerc. 1997; 29: 524-31.

57. Sung RYT, Lau P, Yu CW, Lam PKW, Nelson EAS. Measurement of body fat using leg to leg bioimpedance. Arch Dis Child. 2001; 85: 263-7.

58. Parker L, Reilly JJ, Slater C, Wells JCK, Pitsiladis Y. Validity of six field and laboratory methods for measurement of body composition in boys. Obes Res. 2003; 11 : $852-8$.

59. Conway JM, Norris KH, Bodwell CE. A new approach for the estimation of body composition: infrared interactance. Am J Clin Nutr. 1984; 40: 1123-30.

60. Fuller NJ, Dewit O, Wells JC. The potential of near infrared interactance for predicting body composition in children. Eur J Clin Nutr. 2001; 55: 967-72.

61. Thomas DW, Ryde SJ, Ali PA, Birks JL, Evans CJ, Saunders NH, Al Zeibak S, Dutton J, Hancock DA. The performance of an infra-red interactance instrument for assessing total body fat. Physiol Meas. 1997; 18: 305-15.

Recebido em 8 de janeiro de 2008

Versão final apresentada em 2 de setembro de 2008

Aprovado em 29 de setembro 2008 